\title{
A MULTISECTORAL APPROACH IN DENGUE MANAGEMENT IN SEREMBAN MALAYSIA: AN ECOBIOSOCIAL PERSPECTIVE
}

\author{
Rozita Hod ${ }^{1)}$, Mazrura Sahani' ${ }^{2}$, Hidayatulfathi Othman²), \\ Hanizah Mohd Yusoff ${ }^{1)}$, Idayu B.I ${ }^{11}$, Zainudin Mohd Ali3), \\ Kamarulismail Udin'3) \\ ${ }^{1)}$ Department of Community Health, Medical Faculty, \\ National University of Malaysia \\ ${ }^{2)}$ Faculty of Health Sciences, National University of Malaysia \\ 3)Ministry of Health Malaysia
}

\begin{abstract}
Background: Dengue has been established as a major public health issue in many parts of the world particularly those in the tropical regions. In Malaysia, the rising rate of dengue cases had remained uncurbed, alarming to both the public and the local authorities. Despite the existence of legislations and control activities, why does the number of dengue cases keep on increasing every year? The objective of this study was to assess the existing environmental and health policies/strategies towards sustainable prevention and control of dengue/DHF in Malaysia. In addition, it also aimed to review the eco-bio-social approach and its advantages in prevention and control of dengue.

Subjects and Method: Series of in-depth interviews were conducted on 12 key-informants aged between $36-58$ years old. They were selected based on their roles that were divided into three categories, i.e. (1) policy makers, (2) middle managers, and (3) implementers at the ground level. Each interview explored in detail, on the important domains which were the ecology, biology, and social factors. Each session took an average of 45 minutes to 1 hour. There were a total of 10 males and 2 females selected for the in-depth interview. Open-ended questions were asked and the interviews were voice recorded, after obtaining consent from the respondents. The interviews were terminated once data saturation was achieved. The qualitative data was analyzed using Atlas.ti software.

Results: The three main themes that emerged and were identified to contribute to sustainable dengue control and prevention were (1) adequate implementation of existing health policy, (2) good integration and coordination between agencies, (3) commitment from political and community leaders. Local data showed that areas which did not have these important components became hot spots for dengue with high number of dengue cases.
\end{abstract}

Conclusion: It is vital that the community and relevant authorities focus on these themes/domains that will significantly improve the chances of having sustainable denguecontrol and management program in their localities.

Keywords: multisectoral approach, ecobiosocial, engue control, sustainable management

Correspondence: Rozita Hod. Department of Community Health, Medical Faculty National University of Malaysia. Email: rozita.hod@ppukm.ukm.edu. Mobile: 60196073701. 